\title{
INTERNATIONAL RED CROSS ASSISTANCE IN INDO-CHINA
}

\author{
Mission by Mr. Stroh \\ Mr. Olof Stroh, Director of IOG (Indo-China Operational Group), \\ left Geneva on 19 June 1973 on a mission which took him to Hanoi, \\ Vientiane, Saigon and Phnom Penh.
}

In Hanoi, he had talks with government authorities and representatives of the Red Cross of the Democratic Republic of Vietnam mainly on the construction of prefabricated houses for fifty to one hundred thousand homeless persons, and witnessed the preparatory work that was already in progress for the erection of those dwellings. He also conferred with government authorities and officials of the Red Cross of the Provisional Revolutionary Government on the various technical and medical aspects of a project for equipping a 250-bed hospital.

In Vientiane, Mr. Stroh met members of the Lao Red Cross and officials in charge of International Red Cross Assistance, with whom he discussed the operation of different relief programmes. He visited Luang Prabang, Pak Lay and Seno where he saw the work undertaken by the various medical teams made available by the British, French, Japanese and Swiss Red Cross Societies. He was also received in Vientiane by representatives of the Pathet Lao.

In Saigon, Mr. Stroh conferred with members of the Red Cross of the Republic of Vietnam and with the Head of International Red Cross Assistance concerning relief operations for displaced persons.

In Phnom Penh, the final stage of Mr. Stroh's mission, he discussed with Khmer Red Cross leaders the various problems generated by the growing number of refugees and the ways open to the Red Cross to forward aid to them. He also visited the Swiss medical team working at the Phnom Penh pediatric ward and the Belgian Red Cross surgery team at Svay Rieng. 


\section{Medical Assistance}

On 2 July, a medico-social team, consisting of a doctor, a nurse and a child welfare worker, arrived in Saigon, to work at the orphanages of Go Vap and Phy My. In addition to providing medical treatment, it endeavours to improve conditions for the children and to organize their everyday life. It will also train local personnel to do similar work in the city's other orphanages.

In Laos, four teams are providing medical care for the population: one from the Swiss Red Cross at Luang Prabang, one from the Japanese Red Cross at Pak Lay, and two mobile teams, one from the British and one from the French Red Cross Societies, in the province of Paksane.

In Cambodia, a Belgian Red Cross medical team is at work at Svay Ring and a Swiss Red Cross team in the pediatric hospital at Phnom Penh.

\section{Tracing of missing persons}

The three tracing service offices set up with the National Societies at Saigon, Vientiane and Phnom Penh, are continuing to operate, with technical guidance from the Central Tracing Agency at Geneva.

The Red Cross of the Republic of Vietnam has already sent to the Geneva Central Tracing Agency about a thousand requests for enquiries to be made about missing persons. The requests have been transmitted to the Red Cross of the Democratic Republic of Vietnam. The tracing bureau of the Red Cross of the Republic of Vietnam is continuing the registration of displaced persons in Saigon and in the provinces and the recording of their requests for information and for enquiries to be made about missing persons.

The main task of the Phnom Penh tracing bureau consists in the registration of displaced persons. Several thousand names have been recorded so far. Numerous enquiries about civilians and men of the armed forces outside Khmer territory have been forwarded to Geneva.

The Vientiane tracing bureau has distributed several thousand message forms and enquiry forms.

The Governments of Laos and of the Republic of Vietnam have decided to exempt all mail carrying the red cross emblem from inland postal charges. 